\title{
Stereolitografi (SLA) Tekniği ile Basılan 3 Boyutlu Polimer Yapılarda İkincil Kürleme Süresinin Mekanik Özelliklere Etkisi
}

\author{
İsmail AKTİTiZ ${ }^{* 1,2}$, Kadir AYDIN ${ }^{2}$, Alparslan TOPCU $^{1}$ \\ ${ }^{1}$ Adana Alparslan Türkeş Science and Technology University, Engineering Faculty, \\ Mechanical Engineering Department, Adana \\ ${ }^{2}$ Çukurova University, Engineering Faculty, Mechanical Engineering Department, Adana
}

Geliş tarihi: 25.11.2020 Kabul tarihi: 30.12 .2020

$\ddot{\mathbf{O z}}$

Sıvı fotoduyarlı reçine ve lazer ışığı kullanılarak yüksek boyutsal hassasiyetin elde edildiği Stereolitografi (SLA) yöntemi, eklemeli imalat yöntemleri arasında en dikkat çeken tekniklerden birisi olmuştur. Bu çalışmada, SLA cihazı kullanılarak 3B polimer parçalar basılmış, ikincil kürleme süresinin polimer yapıların mekanik (çekme testi, çentik darbe testi) ve termal (diferansiyel taramalı kalorimetre (DSC) analizi) özelliklerine etkisini incelemek için farklı sürelerde (30,60, 180 ve $300 \mathrm{dk}$ ) UV ikincil kürleme işlemi uygulanmıștır. İșlem uygulanmış polimerlerin elastisite modülü değerinde yaklaşık \%49'luk bir artış gerçekleşmiş ve $63,71 \mathrm{MPa}$ mertebelerine ulaşılmıştır. DSC analiz sonuçları 180 dakika ve üzeri ikincil kürleme proseslerinin karbon-karbon çift bağlarının oluşması için yeterli olduğunu göstermektedir.

Anahtar Kelimeler: Eklemeli imalat, Stereolitografi (SLA), Fotoduyarlı reçine, Ultraviyole kürleme

\section{The Effect of Post-Curing Time on Mechanical Properties in 3D Polymer Materials Printed by Stereolithography (SLA) Method}

\begin{abstract}
Stereolithography (SLA) is one of the most attractive methods in additive manufacturing approaches since obtained high dimensional sensitivity using liquid photosensitive resin and laser light. In this study, 3D polymer materials were fabricated by SLA device, and the ultraviolet post-curing process was applied at different durations $(30,60,180$, and $300 \mathrm{~min})$ to investigate the effect of post-curing time on mechanical (tensile, Charpy impact tests) and thermal (DSC) properties of polymer materials. Elasticity Modulus value of post-cured polymer materials was increased by approximately $49 \%$ and achieved the level of $63.71 \mathrm{MPa}$. It was shown with the results of DSC analysis that the post-curing processes with the $180 \mathrm{~min}$. and above is adequate since the carbon-carbon double bonds occurred.
\end{abstract}

Keywords: Additive manufacturing, Stereolithography (SLA), Photosensitive resin, Ultraviolet curing

*Sorumlu yazar (Corresponding author): İsmail AKTiтiZ, iaktitiz@atu.edu.tr 


\section{GíRiș}

Eklemeli imalat geleneksel üretim yöntemlerinden farklı olarak özel avantajlara sahip yeni geliştirilmiş bir üretim prosesidir [1-5]. Yaygın olarak 3 boyutlu (3B) baskı olarak bilinen eklemeli imalat, parçaları direkt olarak dijital dosyadan katman katman üretim aşamasıdır. $\mathrm{Bu}$ üretim yöntemi 3B modelden bitmiş ürüne geçiş sürecini basitleştirirken, birçok endüstride etkisi olan hızla büyüyen bir alandır. Geleneksel imalat yöntemlerinin aksine, büyük miktarlarda parça üretmek için bir kalıp üretimini gerektiren biçimlendirme süreçleri veya ham bir malzeme parçasını istenen şekle getirilirken önemli miktarlarda sarf malzeme israfı gibi durumları ortadan kaldırmaktadır [6-10]. Son yillarda 3B baskı enerji, biyomedikal, otomotiv gibi birçok uygulama alanlarına entegre olmuştur [11-14]. Stereolitografi (SLA) $[15,16]$, eriyik yığma modeli (FDM) [17,18], seçici lazer sinterleme (SLS) $[19,20]$, katmanlı nesne imalatı (LOM) [21,22], üç boyutlu bask1 (3DP) [23,24] ve lazer metal biriktirme (LMD) $[25,26]$ yaygın olarak kullanılan eklemeli imalat yöntemleri arasındadır.

Stereolitografi (SLA), eklemeli imalat yöntemleri arasında en dikkat çeken teknolojilerden bir tanesidir. $\mathrm{Bu}$ teknikte, akışkan fotoduyarlı malzeme, lazer 1şığı ile vektörel taranarak kürlenip, yüksek boyut hassasiyetlerinde $3 \mathrm{~B}$ polimer yapılar elde edilmektedir. Bu yöntemin en büyük sınırlamaları ise lazer 1 şık boyutu ve $\mathrm{Z}$ eksenindeki katman yükseklik artışıdır [27,28]. SLA yönteminin bu avantajlarına rağmen basılan 3B polimer yapıların mekanik performansları istenilen düzeylerde olmadığı için daha ileri proses işlemleri gerekmektedir. SLA yöntemi ile basılan 3B polimer yapılardaki polimerizasyon süresi bu yapıların mekanik özellikleri, yüzey kalitesi, boyut hassasiyeti gibi malzeme özelliklerini etkilemektedir. SLA ile basılan parçaların kürleme seviyesi termal 1sıl işlem ve ultraviyole (UV) radyasyon gibi ikincil kürleme teknikleri ile değiştirilebilmektedir [29-31]. UV kürleme ile basılan parçalarda daha az çarpılmalar ve kabul edilebilir mekanik özellikler elde edildiği için daha fazla tercih edilmektedir [32].
Son yıllarda araştırmacılar SLA yönteminin geniş uygulama alanlarından dolayı bu yöntem ile basılan parçaları daha da fonksiyonel hale getirmek için birçok çalışma yapmışlardır. Zhao ve arkadaşları ikincil kürleme prosesleri ile malzemenin maksimum çekme dayanımı, sertlik, boyutsal varyasyon, yüzey pürüzlülüğü gibi malzeme özelliklerini incelemişlerdir. UV ile yapılan kürleme işleminde \%70'lere varan mekanik özelliklerde iyileşme meydana gelirken mikrodalga ile yapılan kürleme işleminde \%15 oranlarında iyileşmeler elde etmişlerdir [29]. Salmoria ve arkadaşları yapmış oldukları çalışmada, ikincil kürleme prosesleri ile çizgi tarama aralığının etkisini araştırmışlardır. 0,05 mm çizgi tarama aralığı olan numunelerde ikincil kürleme prosesleri ile yüksek kürleme seviyesi elde edilirken 0,15 ve $0,10 \mathrm{~mm}$ tarama aralığ numunelerde ise numune iç ve yüzey yapısından kaynaklanan homojen olmayan kürleme ve bu kürleme seviyelerinde düşüşler gözlemlemişlerdir. İkincil kürleme prosesleri özellikle termal işlem, $0,10 \mathrm{~mm}$ çizgi tarama aralığında anizotropi derecesini minimize ederek kürleme derecesini artırmış, basılan polimer yapıların boyutsal davranışlarının daha iyi kontrol edilebilmesine olanak sağladığını gözlemlemişlerdir [32]. De Leon ve arkadaşları fotoduyarlı reçine içerisine katkı yapmış ve basılan polimer yapılara ikincil kürleme işlemi uygulamışlardır. Kürleme yapılmayan polimer yapılar ile kıyaslandığında çekme testi sonrasında elde edilen tüm değerlerde yaklaşık \%90 oranında artışlar elde etmişlerdir [33]. Mendes-Filipe ve ark. stereolitografi yönteminde kullanılan farklı foto duyarlı reçinelerde farklı ikincil kürleme parametrelerinin etkilerini araştırmışlardır. UV ikincil kürleme prosesleri ile homojen yüksek çapraz bağlı, daha iyi mekanik özelliklere sahip malzemeler elde edilmiştir [34].

Bu çalışmada, düşük maliyetli, yüksek üretim hızı ve yüksek boyutsal doğruluk gibi büyük avantajlara sahip SLA cihazı kullanılarak 3B polimer parçalar basılmış, ikincil kürleme süresinin polimer yapıların mekanik (çekme testi, çentik darbe testi) ve termal (DSC analizi) özellikleri üzerine etkilerini incelemek için farklı 
sürelerde $(30,60,180$ ve $300 \mathrm{dk}) \mathrm{UV}$ ikincil kürleme işlemi uygulanmıştır.

\section{MATERYAL VE METOD}

\subsection{Materyal}

SLA yazıcıda polimer yapıların basımı için Anycubic fotoduyarlı epoksi reçine (Frankfurt, Germany) kullanılmıştır. Fotoduyarlı epoksi reçine $405 \mathrm{~nm}$ kürlenme dalga boyu, $1,1 \mathrm{~g} / \mathrm{cm}^{3}$ siv1 yoğunluğu, 6-10 s kürlenme zamanı ve $552 \mathrm{MPa}$.s viskozite değerlerine sahiptir. Basımı tamamlanan 3B polimer yapı yüzeylerinde reaksiyona girmemiş reçinelerin giderilmesi için \%99,9 saflıkta BestPro IPA izopropil alkol (propan-2-ol CAS No:67-63-0) kullanılmıştır.

\subsection{Metod}

3B polimer yapıların basımında Şekil 1a'da verilen Anycubic Photon S SLA yazıcı kullanılmıştır.
Anycubic Photon S, 2560 x 1.440 (2K) HD LCD ekranı sayesinde yüksek hassasiyet ile " $z$ " ekseninde $25 \mu$ mertebelerinde, $\mathrm{XY}$ inç başına düşen nokta sayısı (DPI) $47 \mu$ ve $\mathrm{Y}$ ekseninde $1,25 \mu$ mertebesinde bask1 yapabilmektedir. Yazıcının baskı hacmi 115 x 65 x $165 \mathrm{~mm}^{3}$ katman çözünürlüğü ise $25-100 \mu \mathrm{m}$ "dir. Bu çalışmada kullanılan test numunelerinin teknik çizimleri Şekil 2'de verilmiştir. Şekil 3'te gösterilen 3B model çizimleri SolidWorks programı ile çizimi yapılmış sonrasında ".stl" formatında yazıcıya aktarılmıştır. Baskı parametrelleri, taban ışıklama süresi $15 \mathrm{sn}$, ışıklama süresi $8 \mathrm{sn}$, katman kalınlığı $0,05 \mathrm{~mm}$ olarak seçilmiştir. Basımı tamamlanan polimer yapılar Şekil 4'te verilmiştir. Polimer yapılarda reaksiyona girmemiş polimer zincirlerinin reaksiyonlarını tamamlaması için numuneler Sekil 1b'de verilen Wanhao Boxman kürleme cihazına yerleştirilmiş oda sıcaklığı $25^{\circ} \mathrm{C}^{\prime}$ de farklı sürelerde $(30,60,180$ ve $300 \mathrm{dk})$ ikincil kürleme yapılmıştır.

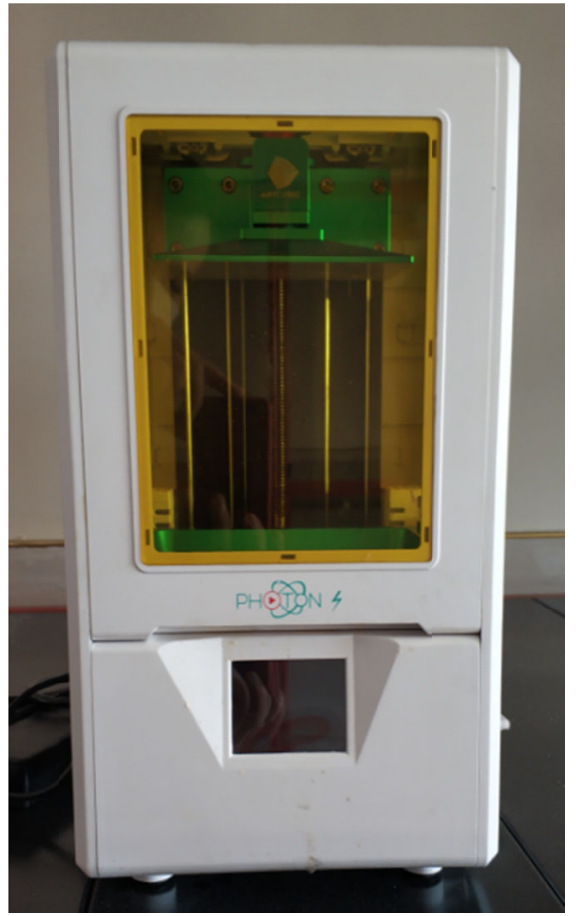

(a)

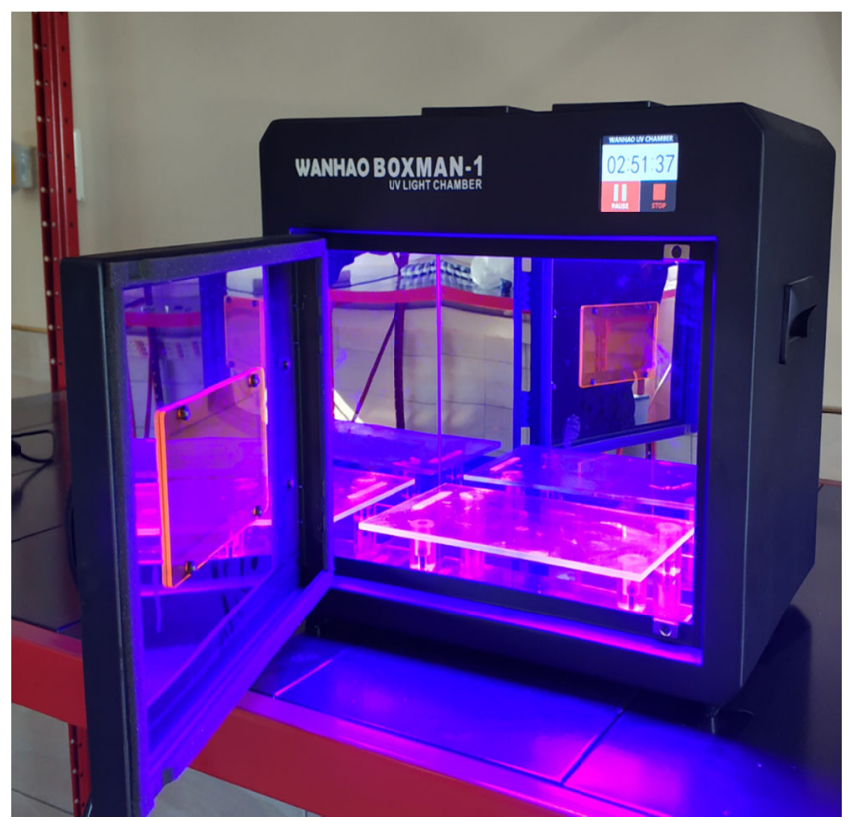

(b)

Şekil 1. a) 3B Stereolitografi (SLA) cihazı, b) İkincil kürleme cihazı 

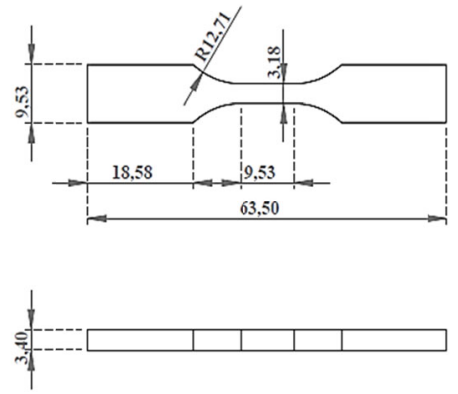

(a)
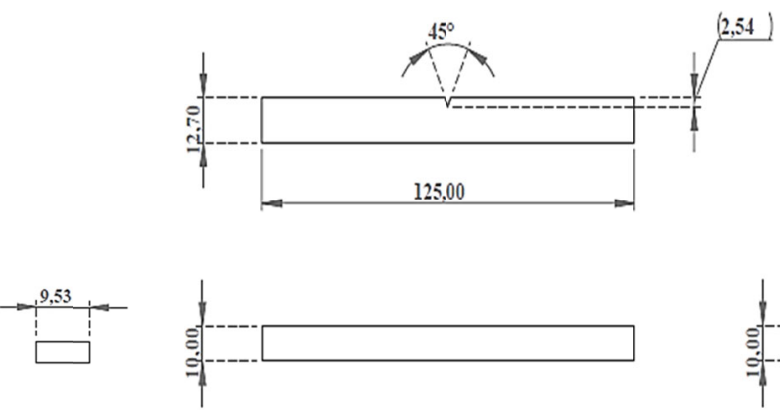

(b)

Şekil 2. a) Çekme, b) Çentik darbe deney numuneleri teknik çizimleri

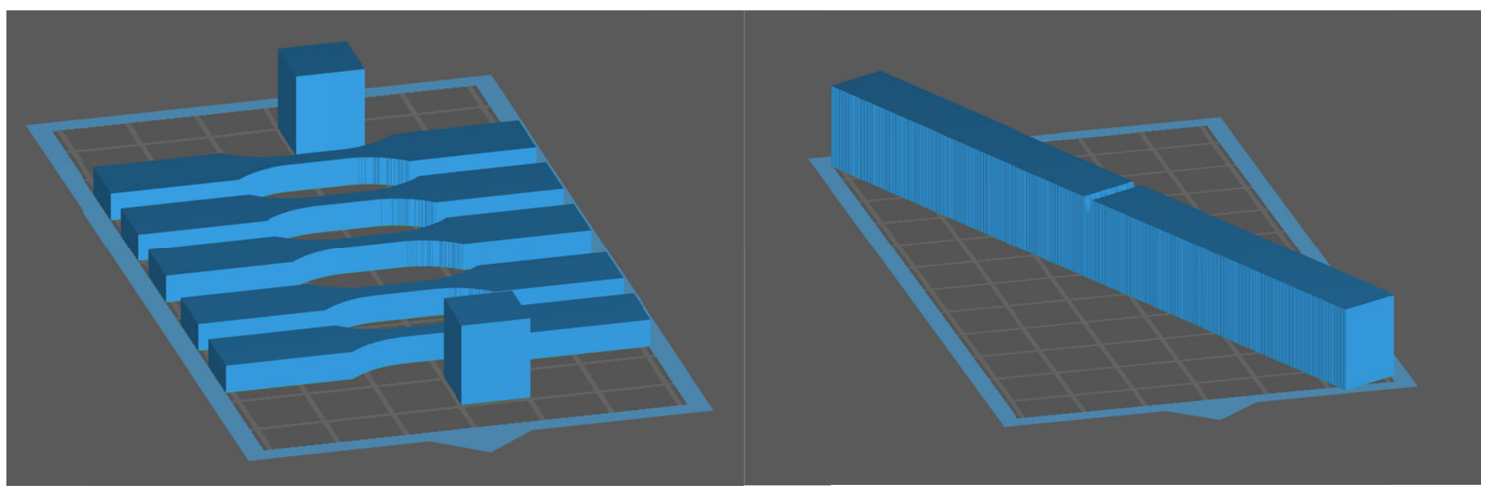

Şekil 3. 3B model çizimleri tamamlanan çekme ve çentik darbe numuneleri

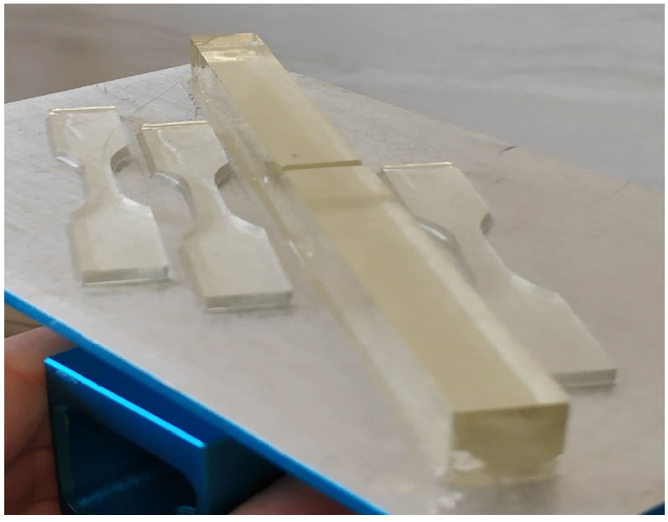

Şekil 4. Basımı tamamlanan 3B polimer yapılar

\section{3. Çekme Testi}

3B basılan polimer yapıların elastite modülü, maksimum çekme dayanımı, yüzde kopma uzaması gibi mekanik özelliklerinin belirlenmesi için ASTM D638 test standartlarında, Şekil 2a'da verilen ölçülere göre hazırlanan numuneler, Şekil 5'te verilen Shimadzu AGS-X 100 kN çekme cihazında $1 \mathrm{~mm} / \mathrm{dk}$. çekme hızında testler gerçekleştirilerek, kürleme süresinin mekanik özelliklere etkisi incelenmiştir.

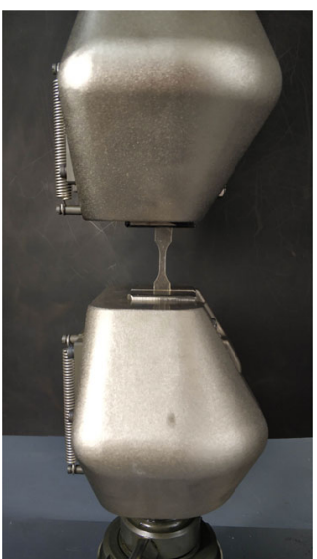

Şekil 5. 3B basılan polimer yapıların çekme testi 


\subsection{Charpy Darbe Testi}

3B basılan polimer yapıların darbe dayanımını belirlemek için Charpy darbe testi, ASTM D6110 test standartlarında, Şekil 2b'de verilen ölçülere göre hazırlanan numuneler, Şekil 6'da verilen MITECH XJJ-50S Digital Charpy Impact Tester cihazında $\quad 25^{\circ} \mathrm{C} \quad$ ortam sicaklığında gerçekleştirilmiş, kürleme süresinin darbe dayanımına olan etkisi incelenmiştir.

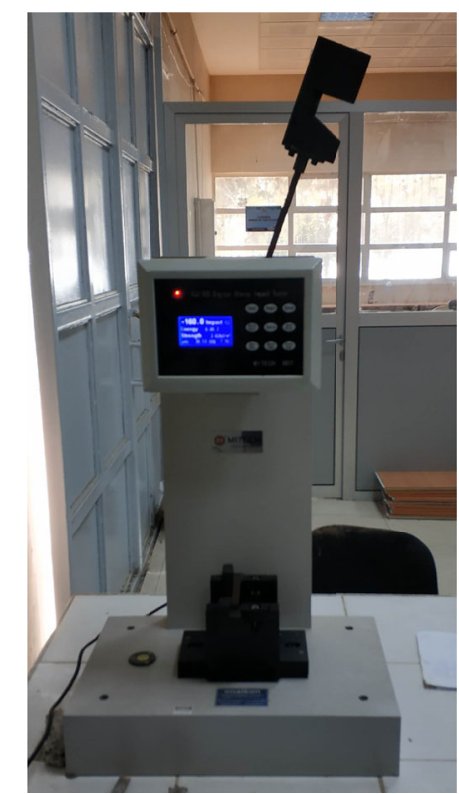

Şekil 6. 3B basılan polimer yapıların Charpy darbe testi

\subsection{Diferansiyel Taramalı Kalorimetre (DSC) Analizi}

3B basılan polimer yapıların kürlenme derecelerini incelemek için diferansiyel taramalı kalorimetre analizi Mettler Toledo DSC 3 cihazında $30^{\circ} \mathrm{C}^{\prime}$ den $300^{\circ} \mathrm{C}^{\prime}$ ye kadar $10^{\circ} \mathrm{C} / \mathrm{dk}$ isitma hizında azot ortamında gerçekleştirilmiştir.

\section{SONUÇLAR}

\section{1. Çekme Testi}

3B basılan polimer yapıların gerilme-yüzde birim uzama grafikleri Şekil 7'de verilmiştir. Elastisite modülü, maksimum çekme dayanımı ve yüzde kopma uzaması gibi mekanik özellikleri Çizelge 1'de, çekme testi uygulanan numunelerin görüntüsü ise Şekil 8'de verilmiştir. Kopma yüzeyleri incelendiğinde numunelerde gevrek kopma gözlemlenmiştir. Her bir durum için 5'er test gerçekleştirilmiştir. Mühendislik gerilmesi yani Eşitlik 1 kullanılarak maksimum çekme dayanımı, Eşitlik 2 kullanılarak elastite modülü elde edilmiştir. Denklemlerde ' $\sigma$ ' mühendislik gerilmesini, ' $F$ ' uygulanan kuvveti, ' $A_{o}$ ' ilk yüzey alanını, ' $E$ ' elastite modülünü ve ' $E$ ' mühendislik gerinimini temsil etmektedir. Elde edilen sonuçlar incelendiğinde artan kürleme süresi ile birlikte polimer yapıların elastisite modülünün, 180 dakika kürleme uygulanan numunelerde yaklaş1k \%71 artış gösterdiği gözlemlenmiştir. Maksimum çekme dayanımına baktığımızda ise 300 dakika kürleme uygulanan polimer yapılarda yaklaşık \%49 artış göstererek 63,71 MPa mertebelerine ulaştığ 1 gözlemlenmiștir. Elastisite modülü ve maksimum çekme dayanımındaki bu artışlar kürleme süresinin artması ille birlikte polimer yapılarda polimerizasyon seviyesinin arttığını göstermektedir [26]. 30 dakika kürleme yapılan numunelerde, yetersiz yapılan kürleme sürelerinden kaynaklanan kürlenmemiş polimer zincirleri uygulanan yük altında açılarak yapıların ikili-üçlü doğrusal davranış sergilemesine sebebiyet vermiștir [35]. 60 dakika kürleme yapılan numunelerde yüzde kopma uzaması $\% 1,8$ olmuştur. 3B baskı işlemi sırasında oluşan polimer zincirler yüksek çapraz bağ yoğunluğuna sahipken, ikincil kürleme işlemi ile oluşan bağlar daha lineer ve zayıf bağlardır

$\sigma=\frac{F}{A_{0}}$

$\sigma=\mathrm{E} . \mathcal{E}$

Birincil oluşan bağ yapılarına kıyasla, ikincil bağ yapılarının daha düşük çapraz bağ yoğunluğuna sahip olmasının sebebi ikincil polimerizasyon sırasında polimer zincirlerinin hareketinin daha yavaş olmasından kaynaklanmaktadır. Bu hetorejenlik, 60 dakika kürleme yapılan numunenin kopma uzamasının bu seviyelerde olmasina sebep olabilmektedir [34]. 
Stereolitografi (SLA) Tekniği ile Basılan 3 Boyutlu Polimer Yapılarda İkincil Kürleme Süresinin Mekanik Özelliklere Etkisi

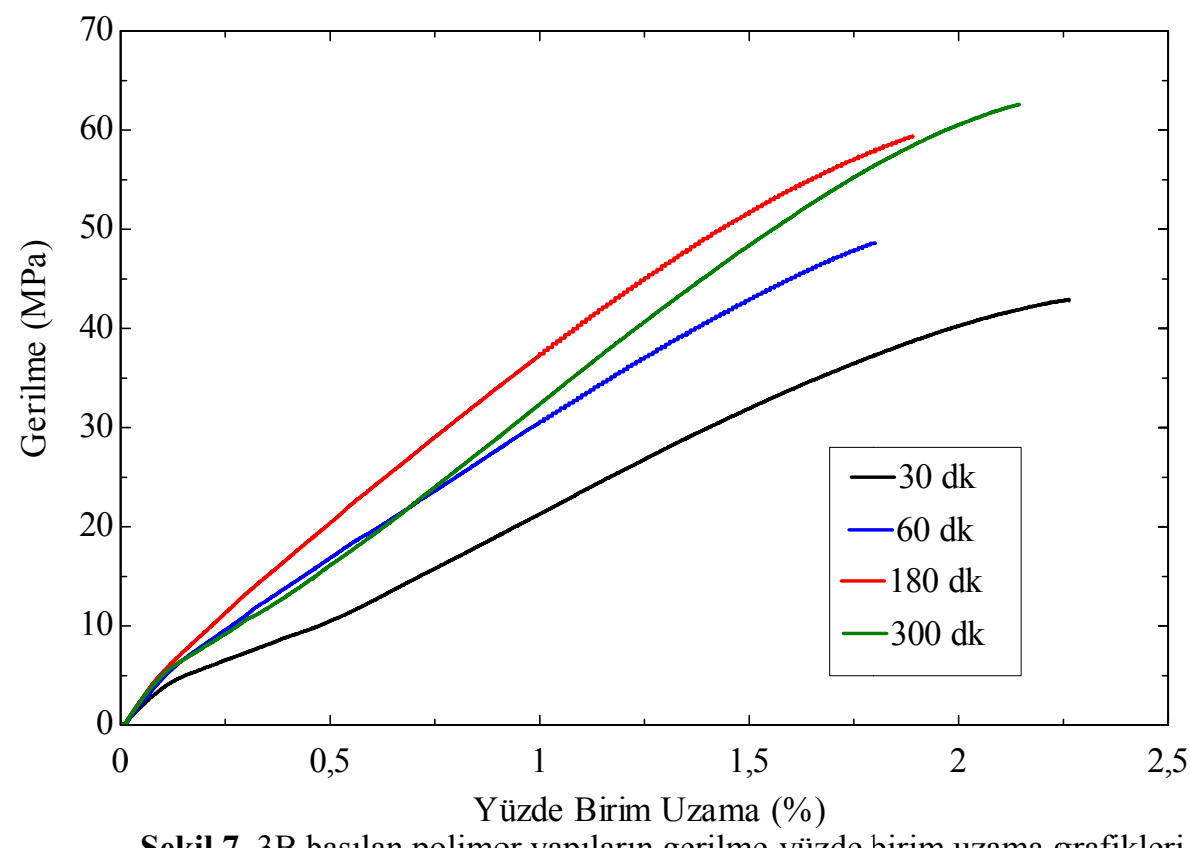

Şekil 7. 3B basılan polimer yapıların gerilme-yüzde birim uzama grafikleri

Çizelge 1. 3B basılan polimer yapıların mekanik özellikleri

\begin{tabular}{|c|c|c|c|c|}
\hline $\begin{array}{c}\text { Numune } \\
\text { Kodu }\end{array}$ & $\begin{array}{c}\text { Elastisite Modülü } \\
(\mathrm{MPa})\end{array}$ & $\begin{array}{c}\text { Maksimum Çekme } \\
\text { Dayanımı }(\mathrm{MPa})\end{array}$ & $\begin{array}{c}\text { Yüzde Kopma } \\
\text { Uzaması }\left(\varepsilon_{\mathrm{K}}\right)\end{array}$ & $\begin{array}{c}\text { Darbe Dayanımı } \\
\left(\mathrm{kJ} / \mathrm{m}^{2}\right)\end{array}$ \\
\hline $30 \mathrm{dk}$ & $559,884 \pm 4,3$ & $42,764 \pm 2,2$ & $2,26 \pm 0,3$ & $20,581 \pm 2,6$ \\
\hline $60 \mathrm{dk}$ & $814,369 \pm 6,4$ & $48,611 \pm 3,1$ & $1,80 \pm 0,1$ & $12,913 \pm 1,6$ \\
\hline $180 \mathrm{dk}$ & $958,335 \pm 8,3$ & $59,375 \pm 2,3$ & $1,89 \pm 0,3$ & $2,32 \pm 0,8$ \\
\hline $300 \mathrm{dk}$ & $899,317 \pm 7,3$ & $63,710 \pm 2,9$ & $2,13 \pm 0,1$ & $2,25 \pm 0,5$ \\
\hline
\end{tabular}
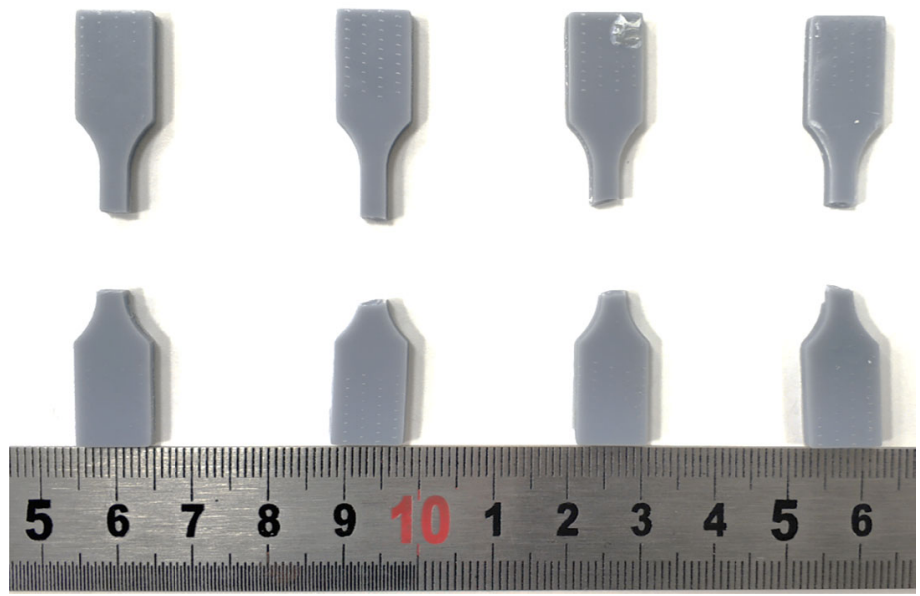

Şekil 8. 3B basılan polimer yapıların Çekme testi numuneleri (sırasıyla 30, 60, 180 ve 300 dakika) 


\subsection{Charpy Darbe Testi}

3B basılan polimer yapıların Charpy darbe test sonuçları Çizelge 1'de, kırık yüzey görüntüleri Şekil 9'da verilmiştir. Her bir durum için 5'er test gerçekleştirilmiştir. Artan kürleme süreleri ile birlikte malzemeler daha gevrek davranış sergilemiş, 30 dakika kürleme yapılan numunelerde darbe dayanımı 20,58 $\quad \mathrm{kJ} / \mathrm{m}^{2}$ seviyelerinde iken 300 dakika kürleme yapılan numunelerde darbe dayanımı 2,25 $\mathrm{kJ} / \mathrm{m}^{2}$ seviyelerinde olduğu gözlemlenmiştir. Artan kürleme süresi ile birlikte polimer yapılarda reaksiyona girmiş polimer zinciri seviyesinin artması, malzemelerin daha gevrek davranış sergilemesine sebebiyet vermektedir [29]. 30 dakika kürleme yapılan numune yüzeylerinde belirgin deformasyon gözlemlenirken, 180 ve 300 dakika kürleme yapılan numunelerde çok az plastik deformasyon gözlemlenmiştir. Bu durum 180 ve 300 dakika kürleme yapılan numunelerin 30 dakika kürleme yapılan numunelere kıyasla daha gevrek davranış sergilediklerini göstermektedir.

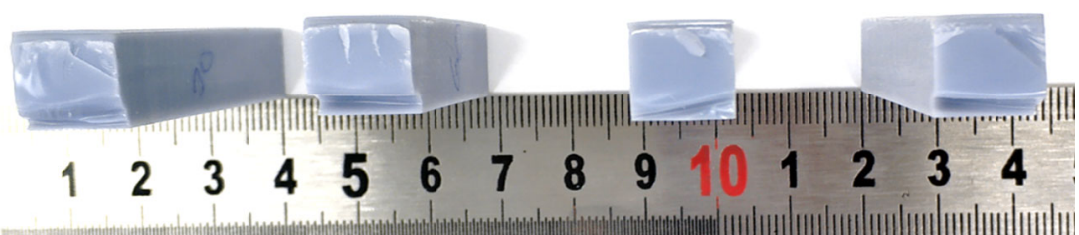

Şekil 9. 3B basılan polimer yapıların Charpy darbe testi numuneleri (sırasıyla 30, 60, 180 ve 300 dakika)

\subsection{DSC Analizi}

3B basılan polimer yapıların diferansiyel taramalı kalorimetre analiz sonuçları Şekil 8'de verilmiştir. Sonuçlar incelendiğinde 30 ve 60 dakika kürleme yapılan numunelerde ekzotermik pik görülürken, 180 ve 300 dakika kürleme yapılan numunelerde herhangi bir ekzotermik pik görülmemiştir.
Ekzotermik pikler reaksiyona girmemiş karbonkarbon çift bağlarını göstermektedir [27]. 30 ve 60 dakika kürleme sürelerinin bu bağların oluşumu için yetersiz kürleme süreleri olduğu, 180 veya daha fazla kürleme süresinin karbon-karbon çift bağlarının oluşumu için yeterli olacağı görülmektedir.

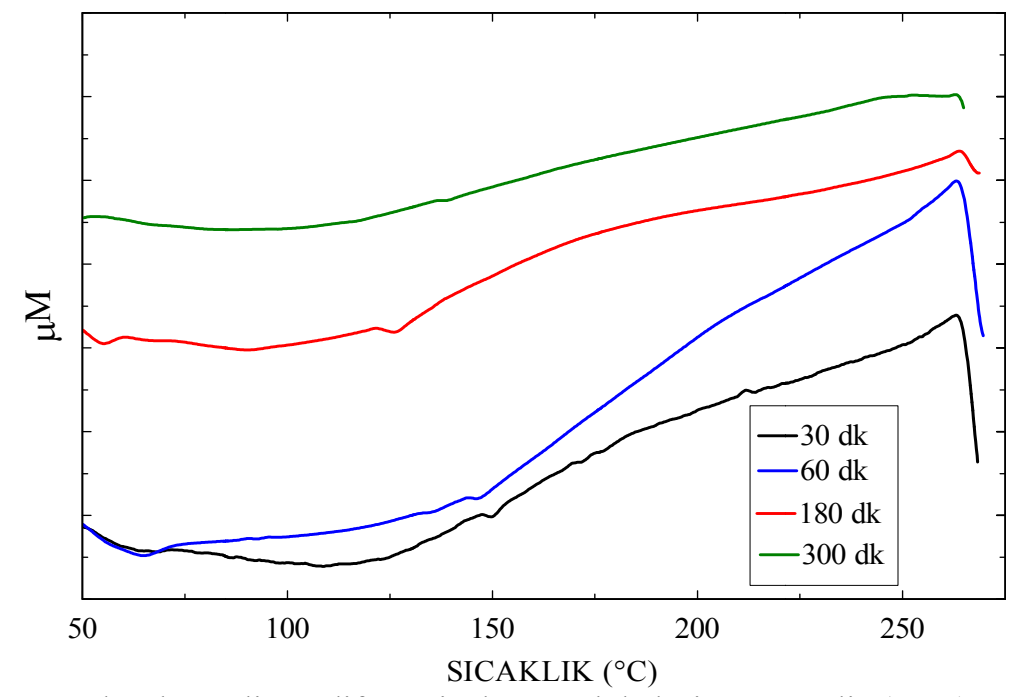

Şekil 10. 3B basılan polimer diferansiyel taramalı kalorimetre analiz (DSC) sonuçları 


\section{TARTIŞMA}

Bu çalışmada SLA yöntemi ile basılan 3B polimer yapıların farklı ikincil kürleme süreleri $(30,60$, $180,300 \mathrm{dk}$ ) altında, yapıların mekanik ve termal özelliklerinde meydana gelen değişimler incelenmiştir. Yapıların mekanik özelliklerinde meydana gelen değişimleri incelemek için çekme testi ve çentik darbe testi, ayrıca 3B basılan polimer yapıların kürlenme derecelerini incelemek için diferansiyel taramalı kalorimetre analizi yapılmıştır.

- Çekme deneyi sonuçları incelendiğinde artan kürleme süreleri ile birlikte $3 \mathrm{~B}$ polimer yapıların elastisite modülü, maksimum çekme dayanımı gibi özelliklerinde iyileşmeler gözlemlenmiştir. Maksimum çekme dayanımı 300 dakika kürleme uygulanan polimer yapılarda yaklaşık \%49 artış göstererek 63,71 MPa mertebelerine ulaşmıştır.

- Çentik darbe testine göre artan kürleme süreleri ile birlikte malzemeler daha gevrek davranış sergilemiş, 30 dakika kürleme yapılan numunelerde darbe dayanımı $20,58 \mathrm{~kJ} / \mathrm{m}^{2}$ seviyelerinde iken 300 dakika kürleme yapılan numunelerde darbe dayanımı $2,52 \mathrm{~kJ} / \mathrm{m}^{2}$ seviyelerine gelmiştir.

- Diferansiyel taramalı kalorimetre (DSC) analizine göre, 30 ve 60 dakika kürleme sürelerinin karbon-karbon çift bağların oluşumu için yetersiz kürleme süreleri olduğu, 180 dakika veya daha fazla kürleme süresinin bu bağların oluşumu için yeterli olacağı anlaşılmaktadır.

- Elde edilen bulgularla 180 dakika ikincil kürleme süresi uygulanan polimer yapıların imalat, enerji, biyomedikal, otomotiv gibi alanlarda kullanılmasına olanak sağladığ düşünülmektedir.

\section{KAYNAKLAR}

1. Choi, N., Kulitckii, V., Kottke, J., Kavakbasi, B.T., Choe, J., Yu, J.H., Yang, S., Park, J.H., Lee, J.S., Wilde, G., Divinski, S.V., 2020. Analyzing the "Non-equilibrium State" of Grain Boundaries in Additively Manufactured
High-entropy CoCrFeMnNi Alloy Using Tracer Diffusion Measurements. Journal of Alloys and Compounds, 155757, 1-10.

2. Gibson, I., Rosen, D., Stucker, B., 2015. Introduction and Basic Principles. Additive Manufacturing Technologies, 1-18.

3. Kenevisi, M.S., Lin, F., 2020. Selective Electron Beam Melting of High Strength A12024 Alloy; Microstructural Characterization and Mechanical Properties. Journal of Alloys and Compounds, 155866, 19.

4. Eyers, D.R., Potter, A.T., 2017. Industrial Additive Manufacturing: A manufacturing systems perspective. Computers in Industry, 92-93, 208-218.

5. Delgado Camacho, D., Clayton, P., O’Brien, W. J., Seepersad, C., Juenger, M., Ferron, R., Salamone, S., 2018. Applications of Additive Manufacturing in the Construction Industry-A Forward-looking Review. Automation in Construction, 89, 110-119.

6. Gebhardt, A., 2011. Layer Manufacturing Processes. Understanding Additive Manufacturing, 31-63.

7. Frazier, W.E., 2014. Metal Additive Manufacturing: A Review. Journal of Materials Engineering and Performance, 23(6), 1917-1928. doi:10.1007/s1 1665-014-0958-z .

8. Herzog, D., Seyda, V., Wycisk, E., Emmelmann, C., 2016. Additive Manufacturing of Metals. Acta Materialia, 117, 371-392.

9. Gebhardt, A., Hötter, J.S., 2016. Basics, Definitions, and Application Levels. Additive Manufacturing, 1-19.

10. Bose, S., Ke, D., Sahasrabudhe, H., Bandyopadhyay, A., 2018. Additive Manufacturing of Biomaterials. Progress in Materials Science, 93, 45-111.

11. Aktitiz, İ., Varol, R., Akkurt, N., Saraç, M.F., 2020. In-situ Synthesis of 3D Printable Monoand Bi-metallic $(\mathrm{Cu} / \mathrm{Ag})$ Nanoparticles Embedded Polymeric Structures with Enhanced Electromechanical Properties. Polymer Testing, 106724, 1-8.

12. Javaid, M., Haleem, A., 2017. Additive Manufacturing Applications in Medical Cases: 
A Literature Based Review. Alexandria Journal of Medicine, 411-422.

13. Saraç, M.F., Oranlı, A., Aktitiz, İ., Yalçın, B.S., Varol, R., 2019. 3B Basılabilir Füme Silika Takviyeli Foto-Duyarlı Polimerlerin Mekanik Özelliklerinin İncelenmesi. Düzce Üniversitesi Bilim ve Teknoloji Dergisi, 17931805.

14. Saraç, M.F., Mert, M., Bülbül, İ., Aktitiz, İ., Yalçın, B.S., Varol, R., 2019. Stereolitrografi ile 3B Basılabilir Nanokil Takviyeli Polimer Yapıların Mekanik Karakterizasyonu. Iğdır Üniversitesi Fen Bilimleri Enstitüsü Dergisi, 1584-1593.

15. Weng, Z., Zhou, Y., Lin, W., Senthil, T., Wu, L., 2016. Structure-property Relationship of Nano Enhanced Stereolithography Resin for Desktop SLA 3D Printer. Composites Part A: Applied Science and Manufacturing, 88, 234-242.

16. Yun, J.S., Park, T.W., Jeong, Y.H., Cho, J.H., 2016. Development of Ceramic-reinforced Photopolymers for SLA 3D Printing Technology. Applied Physics A, 122 (6), 1-6.

17. Skowyra, J., Pietrzak, K., Alhnan, M.A., 2015. Fabrication of Extended-release Patienttailored Prednisolone Tablets Via Fused Deposition Modelling (FDM) 3D Printing. European Journal of Pharmaceutical Sciences, $68,11-17$.

18. Goyanes, A., Chang, H., Sedough, D., Hatton, G.B., Wang, J., Buanz, A., Basit, A.W., 2015. Fabrication of Controlled-release Budesonide Tablets Via Desktop (FDM) 3D Printing. International Journal of Pharmaceutics, 496(2), 414-420.

19. Fina, F., Goyanes, A., Gaisford, S., Basit, A.W., 2017. Selective Laser Sintering (SLS) 3D Printing of Medicines. International Journal of Pharmaceutics, 529(1-2), 285-293.

20. Gan, X., Wang, J., Wang, Z., Zheng, Z., Lavorgna, M., Ronca, A., Fei, G., Xia, H. 2019. Simultaneous Realization of Conductive Segregation Network Microstructure and Minimal Surface Porous Macrostructure by SLS 3D Printing. Materials \& Design, 107874, $1-10$.
21. Mueller, B., Kochan, D., 1999. Laminated Object Manufacturing for Rapid Tooling and Patternmaking in Foundry Industry. Computers in Industry, 39(1), 47-53.

22. Zhang, Y., He, X., Du, S., Zhang, J., 2001. $\mathrm{Al}_{2} \mathrm{O}_{3}$ Ceramics Preparation by LOM (Laminated Object Manufacturing). The International Journal of Advanced Manufacturing Technology, 17(7), 531-534.

23. Utela, B., Storti, D., Anderson, R., Ganter, M., 2008. A Review of Process Development Steps for New Material Systems in Three Dimensional Printing (3DP). Journal of Manufacturing Processes, 10(2), 96-104.

24. Moon, J., Caballero, A.C., Hozer, L., Chiang, Y.M., Cima, M.J., 2001. Fabrication of Functionally Graded Reaction İnfiltrated SiCSi Composite by Three-dimensional Printing (3DPTM) Process. Materials Science and Engineering: A, 298(1-2), 110-119.

25. Cortina, M., Arrizubieta, J., Calleja, A., Ukar, E., Alberdi, A., 2018. Case Study to Illustrate the Potential of Conformal Cooling Channels for Hot Stamping Dies Manufactured Using Hybrid Process of Laser Metal Deposition (LMD) and Milling. Metals, 8(2), 102.

26. Azarniya, A., Colera, X.G., Mirzaali, M.J., Sovizi, S., Bartolomeu, F., Weglowski, M., Wits, W.W., Yap, C.Y., Ahn, J., Miranda, G., Silva, F.S., Hosseini, H.R.M., Ramakrishna, S. ve Zadpoor, A.A., 2019. Additive Manufacturing of Ti-6Al-4V Parts Through Laser Metal Deposition (LMD): Process, Microstructure, and Mechanical Properties. Journal of Alloys and Compounds, 804, 163191.

27. Taormina, G., Sciancalepore, C., Bondioli, F., Messori, M., 2018. Special Resins for Stereolithography: In Situ Generation of Silver Nanoparticles. Polymers, 10(2), 212.

28. Manapat, J.Z., Chen, Q., Ye, P., Advincula, R.C., 2017. 3D Printing of Polymer Nanocomposites via Stereolithography. Macromolecular Materials and Engineering, 302(9), 1600553, 1-13.

29.Zhao, J., Yang, Y., Li, L., 2020. A Comprehensive Evaluation for Different Postcuring Methods Used in Stereolithography 
Additive Manufacturing. Journal of Manufacturing Processes, 56, 867-877.

30. De Pasquale, G., Bertana, V., Scaltrito, L., 2018. Experimental Evaluation of Mechanical Properties Repeatability of SLA Polymers for Labs-on-chip and bio-MEMS. Microsystem Technologies, 24(8), 3487-3497.

31. Karalekas, D., Aggelopoulos, A., 2003. Study of Shrinkage Strains in a Stereolithography Cured Acrylic Photopolymer Resin. Journal of Materials Processing Technology, 136(1-3), 146-150.

32. Salmoria, G.V., Ahrens, C.H., Beal, V.E., Pires, A.T.N., Soldi, V., 2009. Evaluation of Post-curing and Laser Manufacturing Parameters on the Properties of SOMOS 7110 Photosensitive Resin Used in Stereolithography. Materials \& Design, 30(3), 758-763.

33. León, A.S., de Molina, S.I., 2020. Influence of the Degree of Cure in the Bulk Properties of Graphite Nanoplatelets Nanocomposites Printed via Stereolithography. Polymers, 12(5), 1103.

34. Mendes-Felipe, C., Patrocinio, D., Laza, J.M., Ruiz-Rubio, L., Vilas, J.L., 2018. Evaluation of Postcuring Process on the Thermal and Mechanical Properties of the Clear02 ${ }^{\mathrm{TM}}$ Resin Used in Stereolithography. Polymer Testing,115-121.

35. Weng, Z., Zhou, Y., Lin, W., Senthil, T., Wu, L., 2016. Structure-property Relationship of Nano Enhanced Stereolithography Resin for Desktop SLA 3D Printer. Composites Part A: Applied Science and Manufacturing, 88, 234-242. 